\title{
THEODOR W. ADORNO E A PSICANÁLISE: ALGUMAS NOTAS SOBRE O AGITADOR FASCISTA
}

\author{
Fábio Caires Correia ${ }^{1}$ \\ Pontifícia Universidade Católica do Rio Grande do Sul (PUCRS) \\ (D) https://orcid.org/0000-0002-1768-3720
}

\section{RESUMO:}

Examina-se aqui um estudo realizado por Theodor Adorno acerca das locuções radiofônicas do ativista político de extrema direita nos EUA, o pastor Martin Luther Thomas, à década de 30. Detendo-se nestes discursos por meio do método da análise de conteúdo, Adorno buscava entender os motivos que levaram os indivíduos a perpetuarem as mesmas relações econômicas que suas forças haviam superado, em vez de substituí-los por uma forma de organização social superior e mais racional. Passados mais de 70 anos, este estudo é, sem dúvidas, um instrumental precípuo para compreendermos o atual cenário social, principalmente o político.

PALAVRAS-CHAVE: Theodor W. Adorno; Psicanálise; Crítica; Fascismo.

\section{THEODOR W. ADORNO AND THE PSYCHOANALYSIS: SOME NOTES ON THE FASCIST AGITATOR}

\begin{abstract}
:
This article examines a study by Theodor Adorno about the radio phonic utterances of the extreme right-wing political activist in the USA, Pastor Martin Luther Thomas, in the 1930s. In examining these discourses through the method of content analysis, Adorno sought to understand the motives that led individuals to perpetuate the same economic relations as their forces had overcome, instead of replacing them with a superior and more rational form of social organization. After more than 70 years, this study is undoubtedly an indispensable instrument for understanding the current social scenario, mainly politic.
\end{abstract}

KEYWORDS: Theodor W. Adorno; Psychoanalysis; Critical; Fascism.

\footnotetext{
${ }^{1}$ Doutorando em Filosofia, Ética e Filosofia Política pela Pontifícia Universidade Católica do Rio Grande do Sul (PUCRS), Rio Grande do Sul - Brasil. E-mail: fabio.caires@acad.pucrs.br

CORREIA, Fábio Caires. Theodor w. Adorno e a psicanálise: algumas notas sobre o agitador fascista. Griot : Revista de Filosofia, Amargosa, Bahia, v.16, n.2, p.102-114, dezembro/2017. 
A libido do ouvinte fica satisfeita quando tratada como alguém que pertence ao grupo; é secundário que sua curiosidade esteja direcionada à conceitos positivos ou negativos ${ }^{2}$.

Theodor W. Adorno

\section{Introdução}

Embora não tão evidente, parece haver no bojo da sociedade atual uma atitude orientada para a diluição das subjetividades com fins à construção de um sujeito programaticamente heterônomo. $\mathrm{O}$ discurso de recusa à individualidade, com o propósito de conduzir o sujeito a uma aceitação cega ao enquadramento coletivo, é típico da sociedade administrada (ADORNO \& HORKHEIMER, 1985). O objetivo, em decorrência disso, é converter o sujeito numa peça manipulável, i.e., num tipo de engrenagem útil e conformista para o atual sistema econômico-social, estruturalmente pautado sob a lógica do capital (CORREIA, 2016). E dentro desta estrutura de sociedade, que caminha a passos lentos no que se refere à aceitação do diferente, o postulado de uma massa amorfa satisfaz objetivamente e ainda dá forças ao subjetivo não aceito. A partir deste cenário hermético, quiçá desastroso, a ideia de uma psicologia social psicanaliticamente orientada tem se mostrado como um método cogente para a compreensão micro e macro do social, pois permite a incorporação do fator subjetivo no processo de investigação (ADORNO, 2015; FROMM, 1977; HORKHEIMER, 1990). Destarte, por intermédio do polo subjetivo é possível compreendermos os processos sociais e os motivos que levaram os indivíduos a perpetuarem as mesmas relações econômicas que suas forças haviam superado - em vez de substituí-los por uma forma de organização social superior e mais racional ou, citando Adorno, possibilita-nos investigar "as condições subjetivas da irracionalidade objetiva" (ADORNO, 2015, p. 72).

A relação de Adorno com a psicanálise, como bem lembra Dunker na apresentação à edição brasileira dos Ensaios sobre psicologia social e psicanálise, dá-se em dois momentos bastante distintos: i. em sua ida para Viena, por volta de 1925, onde, além de estudar composição musical com Alban Berg, “se depara com a psicanálise como uma força emergente para as vanguardas artísticas, científicas e culturais" (DUNKER, 2015, p. 13); e, ii. no exílio para os Estados Unidos, entre os anos 1937-1949, período marcado não só pelas tentativas complexas e politicamente explosivas de sua institucionalização [da psicanálise], mas principalmente pela atmosfera assombrosa da Segunda Guerra Mundial. É neste período que surge uma das referências clássicas da atividade dos teóricos críticos em terras norteamericanas, a saber, The Authoritarian Personality - Studies in Prejudice (1950) ${ }^{3}$.

\footnotetext{
2 ADORNO, Theodor. La técnica psicológica de las alocuciones radiofónicas de Martin Luther Thomas. Ediciones Akal, S.A, 2008a, p. 13.

3 "Iniciado em 1944 e publicado em 1950, o trabalho acerca da personalidade autoritária (Adorno et al., 1950/ 1965) traz como hipótese central a existência de uma mentalidade que contemplaria simultaneamente a posição política individual e preconceitos contra minorias; tal mentalidade seria
}

CORREIA, Fábio Caires. Theodor w. Adorno e a psicanálise: algumas notas sobre o agitador fascista. Griot : 
Os estudos sobre The Authoritarian Personality [A personalidade autoritária] tinham por objetivo compreender as estruturas do individuo potencialmente fascista. Portanto, não visavam aos fascistas confessos ou organizações de igual modo declaradas fascistas, mas "sujeitos cuja atitude era tal que indicasse que estariam dispostos a aceitar o fascismo se este se tornasse um movimento social forte ou respeitável" (ADORNO, 2008b, p. 153). Nesse sentido, acordando com Carone, os autores não estavam se referindo ao fascismo de Estado, surgido como ideologia política totalitária e de extrema direita do regime do Terceiro Reich na Alemanha ou do regime de Mussolini na Itália.

Eles se debruçaram sobre os traços fascistas ou sobre a mentalidade
fascista presentes, de forma visível ou subterrânea, nas sociedades
modernas democráticas, tal como os Estados Unidos da América do Norte.
Além disso, se preocuparam em: (1) descobrir os traços essenciais e
históricos do fascismo latente de cidadãos comuns, não participantes de
organizações fascistas, e (2) analisar panfletos e elocuções radiofônicas de
agitadores fascistas, ou seja, de militantes e líderes de organizações
fascistas (CARONE, 2012, p. 14).

O resultado de tal estudo, um conglomerado de métodos qualitativos, que reuniam categorias da psicopatologia psicanalítica e/ou análise de conteúdo, e quantitativos, o uso das escalas estatísticas, ficou classicamente conhecido a partir dos famosos nove traços característicos da personalidade autoritária, leia-se, 1. o convencionalismo, 2. a submissão à autoridade, 3. a agressividade, 4. o antiintelectualismo, 5. o antissentimentalismo, 6. superstição e estereotipia, 7 . preocupação com poder e força, 8. destrutividade e cinismo, e, por fim, 9. a projeção e preocupação exagerada com sexo ${ }^{4}$. Enquanto estes estudos buscavam entender os impulsos psicossociais para o fascismo de modo não muito consciente por parte dos sujeitos, alguns escritos precedentes - realizados acerca das locuções e palestras radiofônicas de ativistas políticos de extrema direita - buscavam investigar o funcionamento das técnicas e dos instrumentos psicológicos utilizados pelos agitadores para a manipulação das massas. Não obstante nos sirvamos dos estudos sobre $A$ personalidade autoritária como recurso, nos limitaremos doravante a ler $A$ técnica psicológica das locuções radiofônicas de Martin Luther Thomas - o qual Adorno se deteve de maio de 1934 a julho 1935 -, com o intuito de investigar e entender não só as artimanhas discursivas utilizadas pelo agitador fascista para atingir o inconsciente do seu ouvinte, mas principalmente a possibilidade atual de tais análises.

mediada por necessidades profundas da personalidade que, por sua vez, se desenvolvem por meio de instituições sociais. Os autores ressaltaram a importância de se testar empiricamente as descobertas da psicanálise; e eis que, de forma original, em se tratando de estudos empíricos, a teoria é base de pesquisa e não somente o seu resultado. A teoria não é redutível à experimentação, mas essa auxilia o seu desenvolvimento" (CROCHIK, 2008, p. 299).

4 Para uma maior compreensão acerca destes "nove traços", Cf. TEIXEIRA, J. B. de C.; POIO, A. (1975). A personalidade autoritária: componentes e gênese psicológica. In: Arquivo Brasileiro de Psicologia Aplicada, out./dez. 27(4): 47-69, 1975.

CORREIA, Fábio Caires. Theodor w. Adorno e a psicanálise: algumas notas sobre o agitador fascista. Griot :

Revista de Filosofia, Amargosa, Bahia, v.16, n.2, p.102-114, dezembro/2017. 
Conquanto o texto acima referido seja composto de quatro partes (i. autoimagem do agitador, ii. o seu método psicológico; iii. o meio religioso do fascismo norte-americano e, iv. o engodo ideológico), concentraremos nossas análises na primeira parte, ou seja, autoimagens do agitador. A justificativa para este recorte ancora-se numa tentativa de compreender o atual cenário político com suas vozes da redenção e, a nosso ver, o primeiro capítulo da referida obra, oferece um instrumental precípuo para tal. Vejamos.

\section{Autoimagens do agitador}

O grande halo do líder fascista é transformar um aparente subjetivismo num mecanismo objetivo de identificação. Falar sobre si, fazer confidências aos ouvintes, salvaguardando a distância, é uma de suas mais astuciosas artimanhas. É por meio dela que ele se faz, ao mesmo tempo, partícipe da massa, mas superior à massa. Eis o porquê de Adorno iniciar suas análises acerca do Pastor Martin Luther Thomas com a sugestiva proposta de uma auto-caracterização do agitador. Pois, é "referindo-se a si mesmo de forma ambivalente, como humano e sobre-humano ao mesmo tempo, fraco e forte, próximo e distante, o líder fascista fornece um modelo da verdadeira atitude que pretende ratificar em seus" (ADORNO, 2008a, p. 12). A fala sobre si converte-se, portanto, em um eminente aparato de integração com a massa. "Desta forma, o toque pessoal é uma camuflagem efetiva" (Ibid., p. 13), ou seja, esconde as contradições com um fim muito bem estabelecido: a manipulação das massas.

\section{Estratagema $\mathbf{n}^{\circ} 1$}

A primeira estratégia do líder fascista é apresentar-se como lobo solitário. Como alguém que está só, que não é financiado por forças externas e que ainda luta contra essas forças. Um homem com as melhores "qualidades" possíveis (herói, íntegro, verdadeiro etc.), mas "tão carente de recursos e meios materiais como aqueles a quem se dirigia" (CARONE, 2002, p. 199). Para propagar esta imagem e fazer com que o discurso chegue ao inconsciente do indivíduo visando criar uma espécie de coletividade integrada dos underdogs, o líder tem como ancoragem discursiva duas realidades: i. o ambiente podre, corrupto e desacreditado da política e dos meios de comunicação; e, diretamente relacionada à primeira, ii., a redenção coletiva possível anunciada por um corpo aparentemente desvinculado das falcatruas próprias do paradigma vigente do corpo social. "A afirmação de que " $n \tilde{a} o$ há dinheiro de políticos atrás de mim' equivale à pretensão de que as declarações pronunciadas são espontâneas - [ou seja, ] não são coordenadas por uma organização monopolista" (ADORNO, 2008a, p. 15). Mas, ao contrário, o discurso do agitador é tão somente mais um meio de "manter a energia libidinal primária em um nível inconsciente, de modo a desviar suas manifestações de uma forma adequada a fins políticos" (ADORNO, 2015, p. 163).

Pois bem, um dos padrões de conduta mais visíveis no estratagema lobo solitário é o abandono da dignidade, ou seja, a simulação da espontaneidade não manipulada por meio da liberação emocional exibida e, mais ainda, recomendada. $O$ 
abandono da dignidade é o mecanismo pelo qual o líder se apresenta como o fraco, muito próximo à massa. "Precisamente esse abandono da dignidade parece ser um dos estímulos efetivos da propaganda fascista em todas as partes" (ADORNO, 2008a, p. 16). Fruto de sua lógica discursiva e consequência do mecanismo do abandono da dignidade, o exagerado emotivismo presente nas locuções de Thomas deriva, também, de sua atitude religiosa e predicadora frente ao presbiterianismo oficial $^{5}$. Segundo Adorno, "em várias ocasiões [Thomas] reitera que "quase chorou' quando recebeu, como donativo, cinquenta centavos daquela pobre e velha viúva" (ADORNO, 2008a, p. 16). No entanto, em nenhum momento ele deixava transparecer o fato de estar usando um meio ou canal de comunicação controlado por uma organização monopolista e econômica, portanto, escondia a todo custo o investimento que ele recebia desses meios de comunicação.

Neste sentido, o lobo solitário não hesita em aproximar-se da realidade do sujeito por meio da liberação emocional - tornando-se racionalmente fraco com o fraco -, e mais ainda, transforma seu próprio emotivismo num modelo de conduta mimético "que ele quer que seus ouvintes desenvolvam por imitação" (ADORNO, 2008a, p. 17). O propósito final da liberação é bastante objetivo: "incitar e promover em excesso a violência" (Ibid., p. 17). Uma violência programada de forma racional, portanto, técnica, com fins a uma atitude totalmente irracional. Para Carone (2002), o estratagema da liberação emocional tinha como ancoragem a falta de gratificação emocional dentro de uma sociedade absolutamente fria. $\mathrm{O}$ que isto quer dizer? Sendo negadas aos indivíduos as possibilidades de prazer e satisfação dentro desta sociedade logicamente organizada, o agitador fascista, por meio da técnica da liberação emocional, concede aos indivíduos tais exultações. Assim,

[q]uando Thomas incitava a audiência a se maravilhar com o clima, com a paisagem californiana, com as flores em botão, etc., ele a distraía de seus reais problemas. Baseava-se, portanto, no desejo ou predisposição psicológica da audiência em dar vazão emocional às frustrações impostas pela vida social, abandonando a rigidez do auto-controle até chegar à histeria como forma extrema de emocionalismo. Em última análise, essas gratificações irracionais eram espúrias porque conduziam à regressão do eu à imersão no coletivo, à substituição de reais satisfações do desejo (CARONE, 2002, p. 200).

Parece manifesto que a estratégia traçada pelo lobo solitário tende a desembocar na subsunção do indivíduo na massa. Mesmo amorfa, é na massa que o indivíduo encontra sustento para transformar a violência sofrida, recalcada, em violência efetiva. E para que essa integração programada seja possível - e é esta umas das maiores artimanhas da propaganda fascista - a linguagem se transforma num instrumento de convencimento.

\footnotetext{
5 É interessante notar que qualquer semelhança com o cenário atual parece não ser uma mera coincidência se pensarmos o abusivo e escandaloso mercado do fenômeno divino presente nos meios de comunicações de massa, de forma especial na televisão. Os discursos religiosos, verdadeiras encenações midiáticas, em sua quase totalidade, são espetáculos programados (choros, gritos etc.) pautados unicamente num fim, qual seja, o dinheiro.
}

CORREIA, Fábio Caires. Theodor w. Adorno e a psicanálise: algumas notas sobre o agitador fascista. Griot :

Revista de Filosofia, Amargosa, Bahia, v.16, n.2, p.102-114, dezembro/2017. 
Ela fixa o modo de ser dos homens tais como eles se tornaram sob a injustiça social, na medida em que os coloca em movimento... A fúria que sentem quando se deixam levar por ela é a velha fúria dirigida contra o jugo, reforçada pelo pressentimento de que a saída indicada pela propaganda é uma falsa saída. A propaganda manipula os homens; onde ela grita liberdade, ela se contradiz a si mesma... É na comunidade de mentira que os líderes (Führer) e seus liderados se reúnem graças à propaganda, mesmo quando os conteúdos enquanto tais são corretos (ADORNO; HORKHEIMER, 1985, p. 209).

Se a racionalidade da linguagem propagandística se funda na manipulação e na dominação, a tarefa crítica da linguagem é voltar-se contra si mesmo, descontruindo tais pretensões. Por isso, o desvelamento dos aparatos eminentemente ideológicos presentes nas alocuções de Thomas é visto por Adorno como uma forma de promover uma cisão entre o objeto e o dito sobre o objeto, porque, na propaganda fascista, o dito sobre o objeto é tomado como uma possibilidade de sucumbi-lo numa identidade universal. Em outras palavras, a linguagem é utilizada para captar, mover e aniquilar o fragmento, ou seja, o sujeito/a subjetividade. A análise das alocuções é, portanto, uma crítica material à linguagem enquanto expressão epistêmica de controle. "Enquanto signo, a linguagem deve resignar-se ao cálculo; para conhecer a natureza, deve renunciar à pretensão de ser semelhante a ela" (ADORNO; HORKHEIMER, 1985, p. 27).

\section{Estratagema $n^{\circ} 2$}

Dentro deste processo identificação mimética e dada a postura profundamente conservadora dos seus ouvintes, Thomas não hesitava em apresentar-se como alguém que respondia fidedignamente aos preceitos de Deus, um inocente perseguido, apolítico, sem qualquer referência passada - um marco vazio que podia ser preenchido pelas mais contraditórias concepções de seus ouvintes.

\footnotetext{
O orador não menciona sua preparação, seus antecedentes políticos, nem sua formação intelectual ou qualquer outro traço pessoal específico para o qual ele poderia ser qualificado como líder político. Em vez disso, dá-se por satisfeito com referências vagas ao chamado de Deus... A configuração da autopropaganda e a imprecisão sobre sua pessoa, tem um significado em si... Thomas usa a imprecisão da imagem de si mesmo para deixar espaço para todo tipo de fantasias por parte da audiência... A indefinição sobre sua própria personalidade é um meio de integração concomitante com a imprecisão de seus objetivos políticos (ADORNO, 2008a, pp. 20-21).
}

Além de esconder suas características pessoais, Thomas direcionava sua fala com a finalidade de obter uma assimilação imediata entre o público e o orador. Revelava-se, com isso, portador de uma índole irredutivelmente altruísta, e justamente devido a esta "custosa qualidade moral", estava sempre sujeito a perseguições ou conspirações de seus inimigos.

CORREIA, Fábio Caires. Theodor w. Adorno e a psicanálise: algumas notas sobre o agitador fascista. Griot : 
Há aqui uma categoria de análise bastante interessante, qual seja, a do homem mediano. Ainda que tal categoria represente uma abstração criada pelo Direito, servindo-se de parâmetro no que se refere à concretização ou não do dever objetivo e à ocorrência ou não da imputabilidade, socialmente, a nosso ver, o homem médio diz respeito ao indivíduo que, visando à autoconservação, subsume a natureza em prol da dominação e mesmo pautado no princípio organizador, transforma os sujeitos em "meros seres genéricos, iguais uns aos outros pelo isolamento na coletividade governada pela força" (ADORNO; HORKHEIMER, 1985, p. 41). De acordo com Iray Carone (2002), o dispositivo psicológico próprio desta construção abstrato-ideológica, que tende a converter o agressor em vítima e a vítima em agressor, consiste em estimular e justificar a violência contra os out-groups - grupo social com o qual um indivíduo não se identifica -, projetando neles o que deles se imagina. Essa projeção pode ser astuciosamente programada pelos agitadores fascistas pela racionalização da violência como mecanismo de defesa. "Embora apareça como super-homem, o líder precisa, ao mesmo tempo, operar o milagre de aparecer como uma pessoa mediana, tal como Hitler posava como uma união de King Kong e barbeiro suburbano" (ADORNO, 2015, p. 169).

\section{Estratagema no3}

Arbeit macht frei $[O$ trabalho liberta]! Eis a expressão-resumo do estratagema da infatigabilidade pregado por Thomas. Não é por acaso que tal expressão estava alocada nos portais de vários campos de concentração à época do regime nazista e que, também não só por mera coincidência, se tornou quase que literalmente, o slogan do atual governo do Brasil. O inocente perseguido justifica sua infatigabilidade por meio de sua luta pela pura causa, qual seja, a cruzada contra os comunistas e radicais de esquerda.

Um dos impulsos mais recônditos do fascismo é perpetuar, real e ideologicamente, a necessidade do trabalho duro para obter uma justificativa para a 'disciplina' e a opressão. Essa atitude, baseada em tendências socioeconômicas, permeia a totalidade do sistema fascista até suas últimas reações psicológicas. Sob o fascismo, psicologicamente, ninguém tem permissão para dormir: uma das torturas favoritas usadas pelos governos autoritários sobre suas vítimas é que seu sono é interrompido em cada momento, até o colapso completamente do sistema nervoso. Esse ódio fascista ao sonho - no sentido mais amplo de deixar algo em paz - se reflete na ênfase do líder fascista em seu próprio caráter incansável, com o qual ele é um exemplo para seus seguidores. Infatigabilidade é uma expressão psicológica do totalitarismo (ADORNO, 2008a, p. 23).

Conduzido a reproduzir o comportamento do líder, o indivíduo não percebe o mecanismo de controle exercido sobre ele. Não percebe porque o sono, o último reduto ainda a salvo da captura dos dispositivos de poder, é atacado e interrompido bruscamente. Para Jonathan Crary, em 24/7 - Capitalismo tardio e os fins do sono, o sono pode representar a durabilidade do social, ser o análogo de outros limiares nos

CORREIA, Fábio Caires. Theodor w. Adorno e a psicanálise: algumas notas sobre o agitador fascista. Griot :

Revista de Filosofia, Amargosa, Bahia, v.16, n.2, p.102-114, dezembro/2017. 
quais a sociedade poderia defender ou proteger-se a si mesma. Como o estado mais privado e vulnerável de todos, "o sono depende crucialmente da sociedade para se sustentar" (CRARY, 2014, p. 34). A perda do sono, devido ao controle exercido pelos governos autoritários ou mesmo pelos líderes fascistas, representa, portanto, o enfraquecimento da pulsão criadora do sujeito, e mais ainda, o enfraquecimento da categoria de possibilidade. É justamente essa a artimanha dos regimes totalitários: controlar o sono, incapacitar o sujeito, e, assim, conduzi-lo à aceitação cega do discurso para fins estrategicamente políticos.

\section{Estratagema n ${ }^{\circ} 4$}

Para Adorno, o último dos estratagemas utilizados por Thomas para atingir o inconsciente do sujeito é a do mensageiro. Veja bem, mensageiro e não salvador. A artimanha do agitador é preservar até o último minuto a proximidade com o ouvinte. Em nenhum momento ele pode se fazer ou demonstrar superior à massa. Tal como São João Batista, Thomas se apresenta como o pequeno grande homem, o portavoz da salvação. Não é exagero lembrar que o próprio Hitler fez uso deste ardil ao se chamar de tocador de tambor da causa da Alemanha, posando-se de "bom moço".

\footnotetext{
Consequentemente, um dos dispositivos básicos da propaganda fascista personalizada é o conceito do "grande pequeno homem", uma pessoa que sugere tanto onipotência quanto a ideia de que é apenas um do povo, norte-americano pleno e viril, não maculado por riqueza material ou espiritual. A ambivalência psicológica auxilia a operar o milagre social. A imagem do líder satisfaz o duplo desejo do seguidor em se submeter à autoridade e ser ele mesmo a autoridade. Isso convém a um mundo em que o controle irracional é exercido, embora tenha perdido sua convicção íntima através do esclarecimento universal. As pessoas que obedecem aos ditadores também percebem que estes são supérfluos. Elas reconciliam essa contradição ao assumirem que elas mesmas são o opressor brutal (ADORNO, 2015, p. 172).
}

A identificação desejada pelo agitador exige que ele se apresente não somente como um sujeito superior, forte, mas concomitantemente como um sujeito inferior, fraco, incapaz. Tão fraco quanto os seus seguidores. Apresentando-se como fraco, também ele (o líder) se torna alguém carente de redenção - até maior dos que aqueles que o segue. Um filho sem pai, mas dele dependente e à serviço de algo superior: "uma união do horrível e do maravilhoso, um delírio de aniquilação mascarado como salvação" (ADORNO, 2015, p. 152).

\section{O agitador fascista, e hoje}

As "falsas luzes" da civilização, longe de iluminar o mundo humano, velam a transparência natural, separam os homens uns dos outros, particularizam os interesses, destroem toda possibilidade de confiança

CORREIA, Fábio Caires. Theodor w. Adorno e a psicanálise: algumas notas sobre o agitador fascista. Griot : 
recíproca e substituem a comunicação essencial das almas por um comércio factício e desprovido de sinceridade ${ }^{6}$.

Em Psicologia de massas do fascismo (1933), o psicanalista Wilhelm Reich definia o fascismo como "um somatório de todas as reações irracionais do caráter do homem médio" (REICH, 1988, p. XX). Tais reações são frutos de um ódio recalcado, oriundas da transformação de uma emoção revolucionária* ${ }^{*}$ nos moldes pautados pelo homem médio - em ilusão pelo medo da verdade. A artimanha do líder fascista é justamente essa: instrumentalizar a linguagem para mascarar o real transformando-o numa falsa aparência, propelindo a massa politicamente organizada a ir de encontro, não mais com o real, mas com a aparência do real. A aparência do real, manipulada pela linguagem propagandística do líder, é o alvo para o exercício da violência fascista. $O$ grande jogo da mentalidade fascista é, neste sentido, negar o real por meio dessa abstração ilusória produzida pelo líder.

\begin{abstract}
A mentalidade fascista é a mentalidade do "Zé Ninguém", que é subjugado, sedento de autoridade e, ao mesmo tempo, revoltado. Não é por acaso que todos os ditadores fascistas são oriundos do ambiente reacionário do "Zé Ninguém”. O magnata industrial e o militarista feudal não fazem mais do que aproveitar-se deste fato social para os seus próprios fins, depois de ele se ter desenvolvido no domínio da repressão generalizada dos impulsos vitais. Sob a forma de fascismo, a civilização autoritária e mecanicista colhe no "Zé Ninguém” reprimido nada mais do que aquilo que ele semeou nas massas de seres humanos subjugados, por meio do misticismo, militarismo e automatismo durante séculos. O "Zé Ninguém" observou bem demais o comportamento do grande homem, e o reproduz de modo distorcido e grotesco. $O$ fascista é o segundo sargento do exército gigantesco da nossa civilização industrial gravemente doente. Não é impunemente que o circo da alta política se apresenta perante o "Zé Ninguém" (REICH, 1988, p. XXI, grifos nossos).
\end{abstract}

As análises de Reich vão totalmente ao encontro dos diagnósticos realizados por Adorno expostos na sessão anterior e, até certo ponto, se complementam na medida em que, de um lado, é possível percebermos um líder mecanicamente armado por meio de suas estratégias discursivas; e, por outro, encontramos um indivíduo enfraquecido afetivamente como hospedeiro para tal discurso. E como sugere o grifo no excerto acima, o circo (atual) da alta política, é construído a partir da figura do "Zé Ninguém", ou seja, daquele individuo desconstituído de subjetividade (vida danificada) fruto de uma sociedade que tem a violência como programa. Doravante será este o foco de nossas reflexões: a atual insurgência da figura do político caricaturizado como porta-voz da redenção.

\footnotetext{
6 STAROBINSKI, Jean. Jean-Jacques Rousseau: a transparência e o obstáculo. Tradução Maria Lúcia Machado São Paulo: Cia das Letras, 1991, p. 35, grifos nossos.

* Conceito usado pouquíssimas vezes pelo Reich que, por fidelidade ao autor, optamos por anotá-lo sem alteração. No entanto, é preciso fazer uma ressalva, qual seja, a de que o conceito emoção reacionária seja mais condizente com a proposta do texto e, principalmente, com a elucidação da mentalidade do fascista por ele proposta, do que o conceito de revolução.
}

CORREIA, Fábio Caires. Theodor w. Adorno e a psicanálise: algumas notas sobre o agitador fascista. Griot :

Revista de Filosofia, Amargosa, Bahia, v.16, n.2, p.102-114, dezembro/2017. 
Há dois mecanismos interessantes, circunscritos à figura do político caricaturizado, que merecem ser melhor elucidados: os mecanismos de identificação e o de projeção. Para tanto, recorreremos à Freud mediado por Adorno para tornar possível esta elucidação. Com assinala Rouanet (2003), a influência de Freud nos textos de Adorno é tão visceral que podemos dizer que a teoria crítica de Adorno e de Horkheimer, se formou, em larga medida, a partir de um confronto dialético (positivo e negativo) com o pensador vienense: ora através de Freud, ora contra ele. É a partir de Freud e contra Freud, destarte, que estes conceitos serão pensados.

Por identificação entendamos o mecanismo pelo qual o sujeito internaliza um objeto externo, tornando-se semelhante a este objeto. Enquanto objeto, a identificação é o objetivo final do capitalismo tardio, i.e., "a assimilação total do indivíduo ao sistema existente" (ROUANET, 2003, p. 138). É este o plano de fundo do Excurso I da Dialética do Esclarecimento. Protótipo do indivíduo burguês, Ulisses representa o mais ardil dos sujeitos, aquele que "renega a própria identidade que o transforma em sujeito e preserva a vida por uma imitação mimética do amorfo" (ADORNO; HORKHEIMER, 1985, p. 63). Mais uma vez a linguagem atua como um mecanismo de operacionalização matemática, igualando a diferença na unidade por meio da síntese.

O político caricaturizado é o protótipo do individuo burguês, porque assim como Thomas, ele não hesita em internalizar a natureza externa, reproduzindo-a cinicamente por meio dos mesmos estratagemas. É o que ultimamente temos visto nos agitadores da costa sudeste ${ }^{7}$. As figuras do político, especialmente nestes agitadores, além de patéticas, beiram o ridículo. Mas é justamente esse o seu programa, porque o patético e o ridículo são mecanismos de identificação. Emular a condição de existência de um cadeirante, ou ainda de um varredor de rua, simulando uma existência idêntica é "romper o encanto do nome" (ADORNO; HORKHEIMER, 1985, p. 58). A identificação é o processo que transforma a libido no vínculo entre líder e seguidores, e entre os próprios seguidores (ADORNO, 2015). É pela categoria da mimese que Adorno e Horkheimer concebem o mecanismo da identificação. Por mimese entendamos, panoramicamente, o processo pelo qual o animal e o primitivo se fundem com a natureza, imitando-a. A imitação é a finalidade da mimese, no entanto, ela também é meio. É finalidade porque objetiva a adaptação dos sujeitos ao todo social; é meio enquanto objeto de sedução por parte do sistema. Ao ser seduzido pelo sistema, o sujeito é movido a liberar o seu impulso mimético original sufocado pela civilização. Neste sentido,

O indivíduo imita o líder. Com seu rolar de tambores, o comício nazista imita os rituais da horda. $O$ agitador nazista imita o judeu, e com isso provoca o riso dos seus adeptos. É o riso do anti-semita, o esgar horrível de quem está condenado, para sempre, à repressão, esse mesmo riso que

\footnotetext{
7 Adorno usava a expressão agitadores da costa oeste para fazer referência ao pastor Thomas e aos demais ativistas da Costa Oeste (ou Costa do Pacífico) que correspondia aos estados de Califórnia, Oregon e Washington. Emulando a expressão do autor, utilizamos a expressão agitadores da costa sudeste para fazer referência a dois atuais líderes da política brasileira que, a nosso ver, representam fidedignamente a imagem (ou uma possível caracterização) de um agitador fascista, tal qual Adorno fez de Thomas.
}

CORREIA, Fábio Caires. Theodor w. Adorno e a psicanálise: algumas notas sobre o agitador fascista. Griot :

Revista de Filosofia, Amargosa, Bahia, v.16, n.2, p.102-114, dezembro/2017. 
Freud tinha desmascarado como uma simples válvula de escape para a extravasão dos impulsos proibidos (ROUANET, 2003, p. 139).

O segundo mecanismo circunscrito à figura o político caricaturizado é o da projeção. A projeção é o mecanismo pelo qual "o sujeito expulsa de si e encontra na natureza externa qualidades, sentimentos e desejos próprios" (Ibid., p. 140). Por meio de uma reflexão interna, ele devolve à natureza o percebido pelas impressões. $\mathrm{Na}$ falta da reflexão, a projeção normal (mimese) se converte numa falsa projeção (falsa mimese) à qual se baseia o antissemitismo. De acordo com Jeanne-Marie Gagnebin,

\begin{abstract}
A primeira mímesis... tem por alvo a defesa do bicho homem, fraco e ameaçado, contra os poderosos inimigos exteriores, contra os monstros que querem devorá-lo como o Ciclope a Ulisses. Na tentativa de escapar ao perigo, o homem "primitivo" se assemelha ao meio e abole a diferença entre si mesmo e o ambiente, aniquilando-se para se tornar invisível. É o famoso ardil de Ulisses que se autonomeia de "ninguém" para escapar à vingança... a segunda... é a mímesis da mímesis, mímesis mortífera, a única permitida na Aufklärung, aquela que está na raiz da identificação do indivíduo com o Führer através de uma eficaz encenação coletiva. Em outras palavras, o cerne da obediência nazista e do ódio racista deve ser procurado nesse núcleo originário que transforma a desagregação mimética primeva, simultaneamente ameaçadora e extática, numa mímesis segunda, definida pela rigidez da identidade e pela consequente exclusão do outro (GAGNEBIN, 2008, pp. 148-149).
\end{abstract}

A correlação entre ambos os mecanismos é latente tanto na imagem de Thomas, quanto na figura do político caricaturizado. A identificação do líder fascista com a massa visa à aniquilação da identidade do sujeito nessa mesma massa. No entanto, a imagem do líder é projeção, i.e., uma representação fidedigna do sujeito que o identifica. É este o motivo de o líder ser próximo e distante: ele não pode ser diferente do homem médio. E é sob tal véu que os agitadores da costa sudeste se escondem.

\title{
Concluindo
}

No meu coração há uma paz de angústia, e o meu sossego é feito de resignação.

Fernando Pessoa

Em síntese, no primeiro momento deste ensaio procurei apresentar, através do texto de Adorno - A técnica psicológica das locuções radiofônicas de Martin Luther Thomas -, quais eram os mecanismos utilizados pelo pastor Thomas para atingir o inconsciente do seu ouvinte. Ao analisar estes mecanismos, Adorno identificou autoimagens construídas por meio dos mecanismos de identificação e projeção. Com estas autoimagens, Thomas conduzia o sujeito não-aceito subjetivamente ao enquadramento na massa. Os quatro estratagemas i). lobo solitário, ii). inocente perseguido, iii). infatigabilidade e iv). o pequeno grande homem, além de fortalecer a

CORREIA, Fábio Caires. Theodor w. Adorno e a psicanálise: algumas notas sobre o agitador fascista. Griot :

Revista de Filosofia, Amargosa, Bahia, v.16, n.2, p.102-114, dezembro/2017. 
imagem do líder fascista, dirigia a massa à reproduzir a violência recalcada de cada indivíduo (neste instante já fortalecido pelo coletivo). Portanto, o subjetivo encontra na massa supostamente objetiva forças para a reprodução da violência.

No segundo momento, em consequência do primeiro, a proposta foi a de atualizar as análises de Adorno pensando as autoimagens do agitador a partir de dois líderes do nosso hodierno cenário político. Neste momento a tese do político caricaturizado nos parece bastante defensável no que se refere a teorização dos mecanismos utilizados pelos agitadores da costa sudeste para atingir o inconsciente do ouvinte e organizá-los numa massa para fins programaticamente políticos. Portadores não só de uma racionalidade instrumental, mas principalmente de uma forma de razão performativa muito própria, estes líderes, ao fazer uso dos mecanismos de identificação e projeção, apresentam-se à massa (já organizada ideologicamente) como porta-vozes da redenção. A justificativa é a mesma: se o cenário político está corrompido e altamente poluído, é necessária a redenção. E para tanto, é preciso que a massa o reconheça como líder. A lógica cínica do discurso destes líderes é a do apoderamento da linguagem propagandística.

Mas como provocar a distorção em uma linguagem já distorcida? Como bem lembra Adorno, "a inteligência é uma categoria moral” (ADORNO, 1992, p. 173). E, a nosso ver, é este o lado subversivo da crítica. As tarefas atuais da crítica é, neste sentido, I. desvelar o real por detrás do falseamento da aparência; II. defender o objeto, o não-idêntico, vítima do sistema e, III. promover a reconciliação entre o sentimento (irracional) e o entendimento (racional). A inteligência é uma categoria moral porque, assim com a faculdade do juizo, ela se opõe ao dado, possibilitando, a partir de um pensar antitético, a superação da estupidez. Se "é na comunidade da mentira que os líderes (Führer) e seus liderados se reúnem graças à propaganda... a verdadeira resistência não conhece nenhuma propaganda" (ADORNO; HORKHEIMER, 1985, p. 209). A crítica, portanto, é o negativo da aparência, o que torna possível o desobscurecimento do real. É a mediação entre sujeito, sociedade e utopia (psicanálise, filosofia e arte, respectivamente). 


\section{Referências bibliográficas}

ADORNO, Theodor; HORKHEIMER, Max. Dialética do Esclarecimento: fragmentos filosóficos. Tradução Guido Antonio de Almeida. Rio de Janeiro: Zahar, 1985.

ADORNO, Theodor. Minima moralia. Tradução Eduardo Bicca. São Paulo: Editora Ática, 1992.

- La técnica psicológica de las alocuciones radiofónicas de Martin Luther

Thomas. Ediciones Akal, S.A, 2008a.

Estudios sobre la personalidad autoritária. Ediciones Akal, S.A., 2008b.

Ensaios sobre psicologia social e psicanálise. Tradução Verlaine Freitas.

São Paulo: Editora UNESP, 2015.

CARONE, Iray. Fascismo on the air: estudos frankfurtianos sobre o agitador fascista. In: Revista Lua Nova, $\mathrm{n}^{\circ}$ 55-56, p. 195-217, 2002.

- A Personalidade Autoritária: estudos Frankfurtianos sobre o Fascismo.

In: Revista Sociologia em Rede, vol. 2, nº. 2, p. 14-21, 2012.

CORREIA, Fábio Caires. Theodor W. Adorno e o problema da (semi)formação. In: Revista Kinesis, vol. VIII, n ${ }^{\circ}$ 16, Julho, p.110-126, 2016.

CRARY, Jonathan. 24/7 - Capitalismo tardio e os fins do sono. São Paulo: Cosac Naify, 2014.

CROCHÍK, José Leon. T.W. Adorno e a psicologia social. In: Revista Psicologia \& Sociedade, v. 20, n. 2, pp. 297-305, 2008.

DUNKER, C. I. L. Apresentação à edição brasileira. In: ADORNO, T. Ensaios sobre psicologia social e psicanálise, p. 11-39. Tradução Verlaine Freitas. São Paulo: Editora UNESP, 2015.

FROMM, Erich. A crise da psicanálise: Freud, Marx e a psicologia social. Tradução de Álvaro Cabral. Rio de Janeiro: Zahar Editores, 1977a.

GAGNEBIN, Jeanne-Marie. Do conceito de mímesis no pensamento de Adorno e Benjamin. In: Perspectivas, no. 16, p. 67-86, 2008.

HORKHEIMER, Max. Teoria crítica: uma documentação. Tradução de Hilde Cohn. São Paulo: Editora Perspectiva, 1990.

PESSOA, Fernando. Livro do desassossego. São Paulo: Companhia de Bolso, 2016.

REICH, Wilhelm. Psicologia de Massas do Fascismo. Tradução Maria da Graça M.

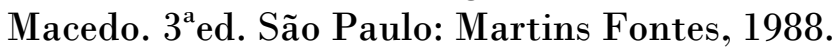

ROUANET, Sérgio Paulo. Adorno e a psicanálise. In: Revista Tempo Brasileiro, out.dez., $\mathrm{n}^{\circ} 155$, p. 1361-156, 2003.

STAROBINSKI, Jean. Jean-Jacques Rousseau: a transparência e o obstáculo. Tradução Maria Lúcia Machado São Paulo: Cia das Letras, 1991.

TEIXEIRA, J. B. de C. \& POIO, A. A personalidade autoritária: componentes e gênese psicológica. In: Arquivo Brasileiro de Psicologia Aplicada, out./dez, 27 (4), p. 47-69, 1975.

Autor(a) para correspondência: Fábio Caires Correia, Pontifícia Universidade Católica do Rio Grande do Sul, Av. Ipiranga, 6681, Partenon, CEP 90619-900, Porto Alegre - RS, Brasil. fabio.caires@acad.pucrs.br

CORREIA, Fábio Caires. Theodor w. Adorno e a psicanálise: algumas notas sobre o agitador fascista. Griot :

Revista de Filosofia, Amargosa, Bahia, v.16, n.2, p.102-114, dezembro/2017. 